\title{
O PROVIMENTO DE HABITAÇÕES SOCIAIS VIA REQUALIFICAÇÃO URBANA
}

\section{THE PROVISION OF SOCIAL HOUSING CHARACTERIZED, THROUGH URBAN REQUALIFICATION}

\author{
A. Aline Skowronski \\ UNIGRAN Capital, Campo Grande, MS, Brasil \\ alinesko@gmail.com \\ B. Luciana Bracarense \\ UNIS - Fundação de Ensino e Pesquisa do Sul de Minas, Varginha, MG, Brasil \\ lubracarense@hotmail.com
}

\section{RESUMO}

Buscou-se responder à pergunta: como se caracteriza o provimento de habitações sociais, via requalificação urbana, e a institucionalização de mecanismos e instrumentos com vistas à sua efetividade? Teve-se por objetivo geral da pesquisa discutir o potencial de efetividade de políticas públicas habitacionais para requalificar edificações de áreas centrais degradadas. Definiram-se dois objetivos específicos: (a) investigar relações existentes entre segregação espacial, políticas públicas, gestão municipal, requalificação urbana e habitações sociais; (b) discutir a institucionalização de mecanismos e instrumentos das políticas habitacionais adotadas pelos municípios de Caeté, Bauru e Salvador. Optou-se por uma metodologia do tipo qualitativa, de natureza teórica, delineada por pesquisa bibliográfica e documental, com um caráter exploratório-descritivo. Pelos resultados obtidos, concluiu-se que, além de pouco significativo, o provimento de HIS pela requalificação de centros históricos, prevaleceu o atendimento formal a protocolos do SNHIS em relação aos mecanismos e instrumentos com vistas ao potencial de efetividade das alternativas propostas.

Palavras-chave: requalificação urbana, habitação de interesse social, institucionalização de políticas públicas.

Linha de Investigação: 1. Cidade e projeto.

Tópico: 3. Planejamento, políticas e governança. 


\section{SÃOPAULO15 $17 \cdot$ LISBOA $25 \sim 26$ JUN 2020}

\section{ABSTRACT}

Searched to answer the question: how is the provision of social housing characterized, through urban requalification, and the institutionalization of mechanisms and instruments with a view to its effectiveness? The general objective of the research was: to discuss the potential effectiveness of public housing politics to requalify buildings in degraded central areas. Two specific objectives were defined: (a) investigate existing relations between spatial segregation, public politics, municipal management, urban requalification and social housing; (b) discuss the institutionalization of mechanisms and instruments of housing politics adopted by the municipalities of Caeté, Bauru and Salvador. We opted for a qualitative methodology, of a theoretical nature, outlined by bibliographical and documentary research, with an exploratory-descriptive character. From the results obtained, it was concluded that, in addition to being insignificant, the provision of HIS for the requalification of historic centers, formal compliance with SNHIS protocols in relation to the mechanisms and instruments with a view to the potential effectiveness of the proposed alternatives prevailed.

Keywords: urban requalification, social interest housing, institutionalization of public politics.

Thematic clusters: 1 . City and project.

Topic: 3. Planning, policies and governance.

\section{Introdução}

Esta introdução contém informações de quatro ordens: a) origem da escolha do tema, b) justificativa para estudá-lo, c) problema e objetivos de pesquisa e d) metodologia de investigação.

$\mathrm{Na}$ origem da escolha deste tema situa-se a constatação de que o papel da Arquitetura e do Urbanismo, no mundo contemporâneo, envolve o enfrentamento das fragilidades e desigualdades do espaço urbano, o que desencadeia um processo de intervenção na realidade, referenciado pela necessidade de superação da segregação espacial.

Sob esse ponto de vista, no Brasil, o Sistema Nacional de Habitação de Interesse Social (SNHIS) proporcionou um crescimento dos programas habitacionais, mas sem superar seu déficit habitacional. Uma das alternativas tem sido o incentivo à ocupação de edifícios históricos, tombados ou não pelo Instituto do Patrimônio Histórico e Artístico Nacional (IPHAN) e congêneres nas esferas estadual e municipal, pela perspectiva da requalificação urbana. Aborda-se o tema, norteando-se pela pergunta: como se caracteriza $O$ provimento de habitações sociais, via requalificação urbana, e a institucionalização de mecanismos e instrumentos com vistas à sua efetividade?

Volta-se, especificamente, para o estudo da institucionalização de mecanismos e instrumentos institucionais capazes de promover a valorização e apropriação do espaço público nas áreas centrais, abandonadas e degradadas. Jacobs (2011) defende que "ideias antigas às vezes podem lançar mão de prédios velhos. Ideias novas devem lançar mão de prédios antigos. [...] O tempo torna obsoletas certas estruturas para certos empreendimentos, e elas passam a servir a outros" (Jacobs, 2011: 208). Este posicionamento está na base da ideia de que tais espaços podem ter sua função social redefinida e suas estruturas reaproveitadas, retornando à sociedade o investimento de outras épocas.

A questão constitui ponto de convergência de fatores econômicos, culturais, sociais, o que torna o tema relevante, ao discutir a relação entre gestão municipal, elaboração e aplicação da legislação urbanística 


\section{XII $\quad$ SÃOPAULO15 $\sim 17 \cdot$ LISBOA $25 \sim 26$ JUN 2020}

frente à precariedade das condições de vida no espaço urbano e o provimento de habitações sociais por meio da ocupação de edifícios de áreas centrais degradadas.

Para responder à pergunta que norteou a investigação, definiu-se como objetivo geral discutir o potencial de efetividade de políticas públicas habitacionais, no âmbito dos municípios, para requalificar edificações de áreas centrais degradadas. Isto exigiu buscar alcançar dois objetivos específicos: (a) investigar relações existentes entre segregação espacial, políticas públicas, gestão municipal, requalificação urbana e habitações sociais; (b) discutir a institucionalização de mecanismos e instrumentos das políticas habitacionais adotadas pelos municípios de Caeté, Bauru e Salvador.

$\mathrm{Na}$ fase exploratória da pesquisa, entre 12 (doze) experiências de municípios brasileiros pré-selecionadas por expressões-chave, foram escolhidas três que mais se identificaram com o recorte conceitual da pesquisa. Procedeu-se, então, a um estudo comparativo entre suas políticas habitacionais.

Este artigo, além dessa introdução e das referências finais, compõe-se de quatro seções.

A primeira, em que se faz um breve referencial teórico para análise do material de pesquisa, subdivide-se em duas subseções: na primeira discorre-se sobre mecanismos institucionais acerca do provimento de habitações sociais na sua relação com elementos referenciais teóricos. Na segunda, aborda-se a gestão municipal e sua responsabilidade na definição e articulação de mecanismos, visando à efetividade do provimento de moradias no espaço concreto em que o cidadão habita. A segunda seção descreve com que materiais, métodos e procedimentos foram realizados os estudos teóricos e tratada a base empírica da pesquisa. Já na terceira, procede-se à discussão dos resultados obtidos que, na quarta e última seção, embasam as considerações finais acerca do problema e objetivos do estudo.

\section{Provimento de habitações sociais via requalificação urbana: a redefinição da função social de espaços públicos}

Sistematizam-se, nas duas subseções que se seguem, informações e reflexões acerca dos elementos teóricos e institucionais que deverão referenciar o estudo. Em primeiro lugar, explicita-se o entrecruzamento existente entre a institucionalização, no nível macro, de um sistema concebido para o enfrentamento do déficit habitacional brasileiro, com a premissa preservacionista de que o novo uso resguarda a integridade física das edificações. Em segundo lugar, na subseção seguinte, fundamenta-se a atuação do município no planejamento para implementar o Plano Nacional de Habitação (PlanHab) — Pacto Nacional pela Moradia Digna.

\subsection{Requalificação urbana e habitações de interesse social: bases teórico-institucionais}

Este estudo exige clareza acerca das concepções explicitadas pelo SNHIS em diálogo com a gestão de espaços públicos e edificações abandonadas e degradadas nas áreas centrais das cidades. Discute-se essa interação sob o ponto de vista das políticas públicas municipais, visando compreender como a gestão urbana tem atuado no processo de ocupação da terra, de modo especial, pelo viés da institucionalização de mecanismos e instrumentos com potencial para garantir a efetividade do atendimento às necessidades habitacionais pela requalificação.

O SNHIS, instituído em 2005, tem por objetivo viabilizar o acesso à terra urbanizada e à habitação digna e sustentável para a população de menor renda, com base nos seguintes princípios: a) compatibilidade e 


\section{XII $\quad$ SÃO PAULO15 17 LISBOA $25 \sim 26$ JUN 2020

integração das políticas habitacionais federal, estadual, do Distrito Federal e municipal, bem como das demais políticas setoriais de desenvolvimento urbano, ambientais e de inclusão social; b) moradia digna como direito e vetor de inclusão social; c) democratização, descentralização, controle social e transparência dos procedimentos decisórios; d) função social da propriedade urbana, visando garantir atuação direcionada a coibir a especulação imobiliária e permitir o acesso à terra urbana e ao pleno desenvolvimento das funções sociais da cidade e da propriedade.

Em 2009, como resultado de debates com a participação de diversos segmentos sociais envolvidos com a questão habitacional, a Secretaria Nacional de Habitação (SNH) do Ministério das Cidades (MCidades) publicou o Plano Nacional de Habitação (PlanHab) - Pacto Nacional pela Moradia Digna. Trata-se de um posicionamento coletivo, norteado pelo desafio posto pelo déficit habitacional acumulado na sociedade brasileira e pela demanda por moradias para atender às novas famílias que se formarão no país até 2023, horizonte temporal do PlanHab.

Entre as diferentes linhas programáticas e ações estabelecidas no referido Plano, situa-se "a promoção de unidades habitacionais em áreas urbanas centrais", que tem por objetivo

viabilizar a promoção pública e privada de moradias em áreas urbanas centrais [...] de modo a repovoar bairros com grande quantidade de imóveis ociosos, equilibrar a convivência entre atividades residenciais e não residenciais, reduzir distâncias e tempos de deslocamentos e otimizar o aproveitamento de locais com boa oferta de trabalho, emprego, comércio, serviços, equipamentos e infraestrutura urbana (Brasil, MCidades, 2009: 153).

O PlanHab considera como "áreas urbanas centrais" dois tipos de porções urbanas:

a) os centros históricos, concebidos como porções urbanas que deram origem à cidade, cujas características concentram legados históricos representativos da memória social;

b) as áreas urbanas consolidadas, constituídas por um bairro ou um conjunto de bairros com alta densidade construída e urbanização consolidada, forte concentração de atividades comerciais e serviços públicos e privados, que abrigam vários grupos sociais e atividades econômicas diversificadas, acessibilidade privilegiada por causa da convergência do sistema viário e de transporte coletivo.

A discussão girou em torno da porção urbana centros históricos. Uma das políticas do PlanHab consistiu no incentivo a empreendimentos habitacionais que se dessem via reabilitação de edifícios com usos mistos, isto é, com térreos, sobrelojas comerciais ou de serviço, que, comercializados como unidades autônomas, ficariam de posse do condomínio, gerando recursos para sua manutenção.

O PlanHab decorre da execução da política urbana definida nos artigos 182 e 183 da Constituição Federal (CF), das normas estabelecidas pelo Estatuto da Cidade, que regulou o uso da propriedade urbana e das diretrizes para elaboração do Plano Diretor, instrumento básico da política de desenvolvimento e de expansão urbana. Assim, o PlanHab traz a CF de 1988 para o âmbito municipal com o objetivo de induzir os Municípios ao cumprimento de suas funções urbanísticas, à ordenação do pleno desenvolvimento das funções sociais da cidade e à garantia do bem-estar de seus habitantes.

No Brasil, iniciativas preservacionistas de revitalização de Centros Históricos, ganharam força a partir de meados da década de 1980. Com o 1ํ Seminário Brasileiro para a Revitalização de Centros Históricos, em 1987, a Carta de Petrópolis tratou de preservação e consolidação da cidadania, ao reforçar a necessidade de 


\section{SÃOPAULO15 17 LISBOA $25 \sim 26$ JUN 2020}

dar ao patrimônio função útil na vida da sociedade contemporânea. Explicitou o conceito de sítio histórico como espaço que concentra testemunhos do fazer cultural da cidade a serem preservados e, a ele, incorporou a concepção de sustentabilidade. E foi pelo viés da sustentabilidade que a noção de preservação deixa de priorizar a imutabilidade e passa a se preocupar com o retorno à sociedade do investimento anteriormente feito, promovendo fruição dos bens e dos equipamentos dos centros históricos.

Essa filosofia de intervenção defende o novo uso como condição de preservação do patrimônio e considera que atribuir uma nova função a espaços e edificações, atende a necessidades atuais e evita que, dissociados da vida cotidiana e das demais políticas públicas, eles se degradem e se tornem fatores de insegurança social. Pelo contrário, segundo Reis (2011) o reuso, ao intervir de maneira sustentável, integra a ação preservacionista a políticas econômicas e sociais. Para o autor

o desafio inicial seria institucionalizar uma política pública consistente, na perspectiva de inserir o acervo patrimonial edilício e urbano na vida contemporânea, resgatando sua utilidade e função social. [...] Patamar político institucional longe de ser alcançado, haja vista a falta de prioridade desse tema na agenda nacional. O que se reflete no estado de abandono de boa parte do acervo patrimonial urbano das cidades brasileiras (Reis, 2011: 7).

O autor considera essa reinserção importante porque concilia função social com políticas públicas de desenvolvimento urbano. Isto é, imprime utilidade ao patrimônio abandonado, contribui para combate ao déficit habitacional, traz movimentação para áreas centrais antes degradadas e contribui para o combate à violência.

Na subseção seguinte esta discussão é trazida para a atuação municipal, espaço onde tais políticas se concretizam e carecem da criação de alternativas locais, capazes de garantir a efetividade do direito de todo cidadão à moradia digna.

\subsection{Segregação espacial, gestão municipal e o provimento de habitações sociais}

Defende-se a ideia de que a dimensão cultural da vida na cidade, pela ótica de premissas preservacionistas, tem evoluído para uma integração com as políticas públicas de desenvolvimento urbano.

$\mathrm{Na}$ base da preocupação com o desenvolvimento urbano não se pode desconhecer que a segregação espacial agrava as condições de vida das camadas mais pobres da população. Por exemplos, o gasto maior com transporte e a falta de infraestrutura em saúde e em educação, o que intensifica as consequências da condição social e contribui para aprofundar a desigualdade, isto é, acaba por fragilizar as relações sociais e favorece maior violência urbana. A segregação espacial não se dá por acaso; pois "é impossível esperar que uma sociedade como a nossa, radicalmente desigual e autoritária, baseada em relações de privilégio e arbitrariedade, possa produzir cidades que não tenham essas características" (Maricato, 2001: 51).

Daí que a elaboração e aplicação da legislação urbanística, frente à precariedade das condições de vida no espaço urbano, remeta a discussão para o papel da gestão municipal no processo de superação da segregação espacial para a população com menos recursos. O Plano Diretor Municipal (PDM) é responsável por prever estratégias de mudança em benefício da qualidade de vida dos cidadãos, assim cumprindo sua função social, o que pode se dar pela perspectiva do provimento de habitações de interesse social via ocupação de espaços em áreas centrais degradadas. Assim, recuperam-se áreas urbanas deterioradas pelo abandono e aproveitam-se terrenos e edificações não utilizadas ou subutilizadas para a construção de 


\section{SÃOPAULO15 17 LISBOA $25 \sim 26$ JUN 2020}

habitações de interesse social (HIS). A medida pode resultar na realocação de famílias que vivem nas ruas, em área de risco, abrigos, favelas ou áreas de preservação permanente.

Ao analisar normas, mecanismos, instrumentos, estratégias explicitadas nos documentos selecionados, preocupa-se em conhecer e discutir o potencial, em termos de efetividade, da institucionalização dessas concepções. Justifica-se tal preocupação pelo fato de que o acesso a recursos financeiros do Fundo Nacional para Habitações de Interesse Social (FNHIS) se deu pela obrigatoriedade de elaboração dos PLHIS.

A concepção, elaboração e execução de propostas deste teor, sob o ponto de vista da atuação técnica, contam com uma dificuldade a mais no que diz respeito à infraestrutura administrativa, sobretudo em municípios de pequeno porte: a carência de recursos humanos especializados. No entanto, a coerência entre o fazer técnico da gestão municipal e a realidade de vida da população exige algo mais, ou seja, a sensibilidade de se referenciar pela busca de melhor qualidade de vida, vista como direito do cidadão e não apenas como uma atribuição a mais da administração pública. No seu conjunto, atuação técnica e sensibilidade social implicam que a gestão municipal tenha ciência de que:

a) o novo uso de edificações abandonadas deve ser antecedido por rigorosa avaliação de segurança estrutural e pela adoção de medidas preventivas em relação à possibilidade de incêndios;

b) o bem-estar da população, pela oferta de condições dignas de moradia, articula-se com o permanente processo de (re) construção da identidade cultural de um dado contexto, ao mesmo tempo em que é fator de construção das identidades individuais. Assim, as políticas locais de promoção da inclusão social constituemse instrumentos de mediação de cidadania.

Parte-se do pressuposto de que o território ocupado pelo município é palco de uma grande diversidade social. Dessa forma, torna-se imprescindível que o gestor público conheça seus habitantes e a forma como estes se organizam em sociedade, para que o provimento de habitação atenda a esse grupo social, em especial, e os resultados de avaliação pós-ocupação sejam satisfatórios para ambos.

Exige-se, então, da gestão municipal, equipe multidisciplinar, porque diferentes perspectivas teóricas, competências e habilidades se entrecruzam e pensam a complexidade do problema habitacional, ao criarem alternativas para solucioná-lo. Não se trata de justaposição de soluções, cada uma vinculada a uma área do saber teórico e do saber-fazer de caráter técnico; a tomada de decisões lida com a interface dos vários aspectos de uma mesma situação e requer integração de vários setores administração, em contraposição à ação isolada.

\section{Materiais e métodos}

Optou-se por uma metodologia do tipo qualitativa, de natureza teórica, delineada por pesquisa bibliográfica e documental, com um caráter exploratório-descritivo. A base empírica do estudo foi constituída por documentos da gestão municipal (PLHIS, PDM, Lei Municipal, entre outros), selecionados conforme percurso metodológico, composto por duas etapas, uma de macro e outra de microanálise, conforme descrito, a seguir.

\section{Primeira etapa (macroanálise)}

> Na fase exploratória desenvolveu-se uma pesquisa documental introdutória, com busca inicial, cujo critério para pré-seleção de experiências a serem analisadas com o uso das expressões-chave: (a) 


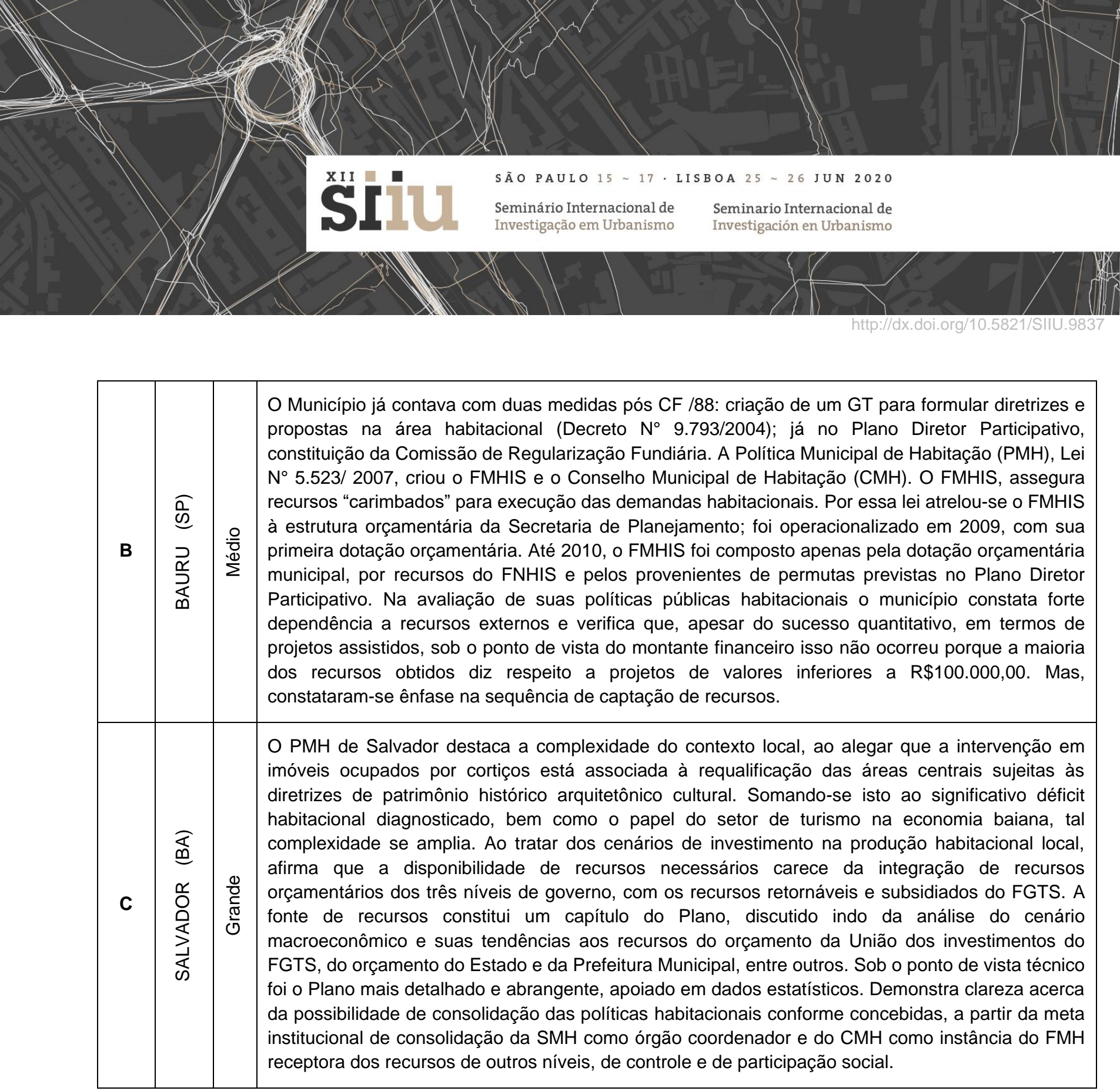

Quadro 1- Caracterização do material selecionado quanto a mecanismos e instrumentos. Elaboração própria a partir da fase de pré análise.

A partir do Quadro 1, analisa-se, primeiramente, se as decisões tomadas foram transformadas em atos legais e se foram previstas as articulações, como convênios para garantir a efetividade de suas metas.

Constata-se, por exemplo, tanto na etapa de macro quanto de microanálise, a prevalência do atendimento formal às exigências do SNHIS. Fala-se de prevalência porque, na maioria das vezes, não se deparou com evidências de aprofundamento em diagnósticos nem se encontraram propostas criativas, coerentes com o contexto ali descrito. Isto se comprova por ter sido desnecessário ampliar o número de municípios na fase exploratória da pesquisa: propostas e até linguagem se repetiam nos mesmos termos.

Além disso, nesta fase, constatou-se também que muitos documentos se referiram à requalificação apenas quando, formalmente, ao elaborarem o ato legal de criação do FMHIS, relacionaram a que poderiam ser destinados os recursos do fundo. Isso bastava; não se apresentava a ação programática correspondente nem estratégias, mecanismos e instrumentos de implementação de alguma intervenção. 


\section{XII $\mathbf{S}$ SÃOPAULO15 17. LISBOA $25 \sim 26$ JUN 2020}

Porém, no que diz respeito à necessidade de captação de recursos externos, Caeté (município de pequeno porte), Bauru (médio porte) e Salvador (de grande porte), todos três, mostraram-se dependentes de outras fontes, motivo pelo qual aderiram ao SNHIS e se submeteram às exigências feitas, em troca de recursos financeiros para o desenvolvimento urbano.

$\mathrm{Na}$ sequência, aconteceu a fase de estudos pormenorizados dos documentos, no contexto da etapa de microanálise em que se considera os seguintes fatores para identificar evidências neles presentes:

a) coerência entre contexto- opções programáticas- institucionalização;

b) convergência ou não de conceitos, estabelecendo-se coesão interna em um dado documento ou coesão entre documentos, conforme o caso;

c) classificação do viés predominante (tecnicista/pragmático, preservacionista ou integrador dos dois anteriores).

Analisa-se que nos dois primeiros casos (componente "A' e "B" do objeto de estudo) os documentos analisados revelaram opções superficiais na questão do provimento através da requalificação de edifícios ociosos ou obsoletos das áreas centrais dos municípios.

Abre-se espaço para se supor que a intenção de uso habitacional dos centros históricos desses municípios sucumbiu diante das políticas habitacionais articuladas com o mercado, com provimento do déficit habitacional por meio de novas moradias. Assim sendo, refletiria um embate muito comum entre poder público e o mercado imobiliário, que tem objetivos distintos para ocupação do solo urbanizado.

Somente no terceiro caso (componente "C" do objeto de estudo), município de Salvador, na Bahia, é que se aprofundou na questão da conciliação entre premissas preservacionistas e políticas públicas de desenvolvimento urbano.

Tais observações introdutórias em relação ao quadro 2, que se segue, são complementadas quando os registros do mesmo são ampliados pelas análises sequentes ao quadro.

\begin{tabular}{|c|c|c|c|}
\hline $\begin{array}{l}\stackrel{0}{\circ} \\
\stackrel{0}{\circ} \\
\stackrel{\circ}{\circ} \\
\frac{0}{0} \\
\end{array}$ & Contexto-opções- institucionalização & $\begin{array}{l}\text { Convergência ou não de } \\
\text { conceitos }\end{array}$ & Viés das opções \\
\hline A & $\begin{array}{l}\text { Existe coerência do projeto com o } \\
\text { diagnóstico habitacional. Definiu-se que o } \\
\text { FMHIS deverá ser aplicado à } \\
\text { "Recuperação ou produção de imóveis } \\
\text { em áreas encortiçadas ou deterioradas, } \\
\text { centrais ou periféricas, para fins } \\
\text { habitacionais de interesse social", } \\
\text { indicando que, no caso de um projeto } \\
\text { futuro, existirá essa garantia de recurso } \\
\text { de origem local. }\end{array}$ & $\begin{array}{l}\text { Existe coerência entre objetivos, } \\
\text { diretrizes, metas e estratégias de } \\
\text { ação, bem como clareza quanto } \\
\text { aos seus problemas habitacionais } \\
\text { e às suas necessidades. As } \\
\text { concepções teóricas que se } \\
\text { evidenciam nos documentos são } \\
\text { convergentes. }\end{array}$ & $\begin{array}{l}\text { Constata-se coerência } \\
\text { técnica entre diagnóstico e a } \\
\text { institucionalização da } \\
\text { previsão de recursos. A } \\
\text { intenção preservacionista } \\
\text { não se traduz em ação } \\
\text { programática. Prevalece o } \\
\text { viés técnico e o caráter } \\
\text { pragmático da adesão ao } \\
\text { PlanHab. }\end{array}$ \\
\hline
\end{tabular}




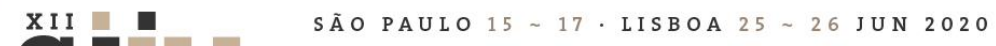

\begin{tabular}{|c|c|c|c|}
\hline B & $\begin{array}{l}\text { Existe coerência do projeto com o } \\
\text { diagnóstico habitacional. Propõe-se } \\
\text { revitalizar e/ou requalificar áreas } \\
\text { degradadas; na prática, dá ênfase à } \\
\text { melhoria das condições de habitabilidade } \\
\text { de moradias pré-existentes, articulando- } \\
\text { se com a iniciativa privada, cooperativas. } \\
\text { Nos marcos normativos locais identifica- } \\
\text { se um rearranjo da estrutura física, } \\
\text { administrativa e de aprimoramento da } \\
\text { legislação municipal com vistas à } \\
\text { efetividade de suas propostas. }\end{array}$ & $\begin{array}{l}\text { Existe coerência entre objetivos, } \\
\text { diretrizes, metas e estratégias de } \\
\text { ação. As opções do plano são } \\
\text { conceitualmente claras com } \\
\text { relação à compreensão } \\
\text { pragmática que se tem de política } \\
\text { urbana. Quanto à requalificação / } \\
\text { revitalização o Plano até fala das } \\
\text { áreas centrais sem maior ênfase. }\end{array}$ & $\begin{array}{l}\text { Prevalece o viés técnico/ } \\
\text { pragmático, ao aderir ao } \\
\text { PlanHab. Existe coerência } \\
\text { técnica entre o diagnóstico e } \\
\text { a institucionalização de } \\
\text { instrumentos para captação } \\
\text { de recursos. Não se dá } \\
\text { ênfase à dimensão cultural e } \\
\text { identitária do problema em } \\
\text { questão. }\end{array}$ \\
\hline C & $\begin{array}{l}\text { Existe coerência entre o diagnóstico } \\
\text { habitacional e ações programáticas. Tem- } \\
\text { se clareza quanto à interface entre } \\
\text { desigualdade social, direito à moradia } \\
\text { digna, necessidade do crescimento } \\
\text { sustentável. Explicita-se a impossibilidade } \\
\text { do município arcar sozinho com a } \\
\text { responsabilidade de solucionar problemas } \\
\text { habitacionais. Nos marcos normativos } \\
\text { locais institucionaliza-se o financiamento } \\
\text { articulado da União, Estado e Município, } \\
\text { sem o que novos usos serão inviáveis. }\end{array}$ & 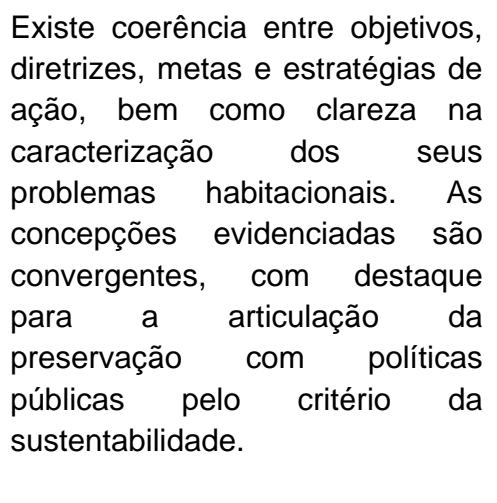 & $\begin{array}{l}\text { Constata-se, diálogo entre o } \\
\text { viés técnico e a dimensão } \\
\text { cultural do problema } \\
\text { habitacional. Declara-se a } \\
\text { integração da Preservação e } \\
\text { Desenvolvimento, com foco } \\
\text { no mercado turístico. }\end{array}$ \\
\hline
\end{tabular}

Quadro 2- Evidências identificadas nos documentos estudados. Elaboração própria a partir da fase de microanálise.

Quanto ao Município de Caeté, entre medidas voltadas para cobrir o déficit habitacional com a construção de novas moradias, estabeleceu-se também que o FMHIS seria aplicado à "recuperação ou produção de imóveis em áreas encortiçadas ou deterioradas, centrais ou periféricas, para fins habitacionais de interesse social". Declarou-se opção pela recuperação de moradias em áreas encortiçadas e degradadas em centro histórico, coerentemente com a condição de cidade do circuito histórico de MG. Nos documentos consultados, inexiste ação programática correspondente, o que aponta para a fragilidade da opção, mesmo com a institucionalização do necessário respaldo jurídico, com a lei que instituiu o FMHIS.

Já no caso do Município de Bauru procedeu-se à identificação da disponibilidade de solo urbanizado e de imóveis passíveis de serem utilizados para HIS tendo, como ponto de partida, a apuração da situação das áreas enquadradas como Zona Especial de Interesse Social (ZEIS). Promoveu-se, também, um levantamento quanto à existência, ou não, de outras áreas públicas vazias com potencial para implantação de HIS. O PLHIS de Bauru é de natureza essencialmente técnica, bem objetivo. Preocupou-se, sobretudo, com: (a) a infraestrutura (órgãos e pessoal especializado) da Prefeitura para o desafio de solucionar o déficit habitacional da cidade; (b) identificação de fontes e processos de captação de recursos. Fez referência à revitalização e/ou requalificação de áreas degradadas, porém pelo viés da recuperação ou melhoria das habitações nelas existentes, focando-se nas condições de habitabilidade dessas moradias. 


\section{SÃOPAULO15 17 LISBOA $25 \sim 26$ JUN 2020}

Por fim, quanto ao terceiro município selecionado — o de Salvador - visando garantir melhor aproveitamento da infraestrutura instalada ficou estabelecido o "Programa de requalificação de edificações de cortiços e moradias coletivas". Seu contexto é bem mais complexo porque a intervenção em imóveis ocupados por cortiços está associada às diretrizes de patrimônio histórico arquitetônico cultural. Tal complexidade fundamentou reconhecer a necessidade de um trabalho conjunto entre estado e município, com a participação da União, para financiamentos com fins habitacionais e para intervenção em imóveis protegidos, respaldado por mecanismos e instrumentos legais, conforme se aborda nos marcos normativos locais.

Apenas neste caso a preservação teve protagonismo declarado do diagnóstico à proposição de ações articuladas com o desenvolvimento urbano. Verificou-se que, mesmo como cidade do circuito histórico nacional, sua economia dependente do turismo traz risco da geração de oportunidades de negócios, emprego e renda, sobrepondo-se à salvaguarda dos bens culturais.

\section{Considerações finais}

O estudo norteou-se pela seguinte pergunta: como se caracteriza e se dá o provimento de habitações sociais, via requalificação urbana, e a institucionalização de mecanismos e instrumentos com vistas à sua efetividade? A partir do objetivo geral de verificar a busca de efetividade de políticas públicas habitacionais, no âmbito dos municípios, para requalificar edificações de áreas centrais degradadas foram elaborados dois objetivos específicos: (a) investigar relações existentes entre segregação espacial, políticas públicas, gestão municipal, requalificação urbana e habitações sociais; (b) discutir a institucionalização de mecanismos e instrumentos das políticas públicas habitacionais adotadas. O objeto de estudo constituiu-se de planos dos municípios de Caeté, Bauru e Salvador, utilizando-se metodologia do tipo qualitativa, de natureza teórica, delineada por pesquisa bibliográfica e documental, com um caráter exploratório-descritivo.

Concluiu-se pela dificuldade de provimento de HIS via requalificação de centros históricos, pois, prevaleceu a opção por novas moradias, indicando o poder do mercado imobiliário.

Compreende-se, também, que o interesse pela captação de recursos federais condicionou muitos municípios a aderirem ao SNHIS, comportando-se apenas formalmente na definição de políticas locais. Considera-se, por fim, que a pretendida reinserção do uso habitacional de porções históricas centrais não se constitui prioridade quando se discute a política pública de combate ao déficit habitacional, inviabilizando a função social da requalificação. Porém, registra-se que as exigências trazidas pela experiência promoveram avanços quanto ao arcabouço legal da HIS em cada um deles. Provavelmente, a avaliação da política pública implementada aponte caminhos para a consolidação de um novo olhar para o problema posto pela pesquisa.

\section{REFERÊNCIAS}

\subsection{Trabalhos completos}

JACOBS, J. Morte e vida de grandes cidades. Tradução de ROSA, C. (2011). São Paulo: Editora WMF Martins Fontes.

MARICATO, E. (2001). Brasil, cidades: alternativas para a crise urbana. Petrópolis: Vozes. 


\section{SÃOPAULO15 17 LISBOA $25 \sim 26$ JUN 2020}

REIS, C. (2011). Gestão de centros históricos no brasil: as cidades patrimônio mundial, o caso de Brasília e São Luís. Tese. Doutorado em Arquitetura. UNB. Faculdade de Arquitetura e Urbanismo. Programa de Pesquisa e Pós-Graduação. Orientadora: Sylvia Ficher. BSB, 233 f.

\subsection{Fontes eletrônicas}

ANDRADAS, SP. Plano Local de Habitação de Interesse Social. Prefeitura Municipal de Andradas. Dezembro de 2012. Disponível em:<http://www.andradas.mg.gov.br/downloadsOficiais/124-lo1715.2015-anexoestrategiaseacoes-etapa3-plhis.pdf > Acesso em: 23/04/2019.

BRASIL, LEI № 11.124, DE 16 DE JUNHO DE 2005. Disponível em: <solucoesparacidades.com.br/wpcontent/uploads/2012/08/lei_11124_habitacao_SNHIS_interesse-social.pdf > Acesso em: 23/04/2019.

BRASIL, Ministério das Cidades, Plano Nacional de Habitalção, 2008. Disponível em: <http://www.urbanismo.mppr.mp.br/arquivos/File/Habitacao/Material_de_Apoio/PLANONACIONALDEHABITA O.pdf >. Acesso em: 23/04/2019.

Plano Local de Habitação de Interesse Social. Disponível em: <http://institutosoma.org.br/wpcontent/uploads/2015/11/Capítulo-4-Quadro-Institucional-e-Normativo.pdf > Acesso em: 10/05/2019.

CAETÉ, MINAS GERAIS. LEI MUNICIPAL № 2.557 0/08. Disponível em: <https://docplayer.com.br/5337162-Leimunicipal-no2-557-0-08.html> Acesso em: 10/05/2019.

https://www.mdr.gov.br/habitacao/biblioteca-snh/61-snh-secretaria-nacional/biblioteca/164-banco-referencial-de-plhis (consulta em: 20/05/2019)

DIAMANTINA, MINAS GERAIS. Plano Local de Habitação de Interesse Social de Diamantina/ MG. 2014. Disponível em:<https://plhisdiamantina.wordpress.com/cadernos/ > Acesso em: 15/06/2019.

FRANCA, SÃO PAULO. PLHIS - Plano Local de Habitação de Interesse Social. Disponível em: <https://docplayer.com.br/8978893-Plano-habitacional-franca-plhis-plano-local-de-habitacao-de-interesse-social.html> Acesso em: 20/06/2019.

https://www.mdr.gov.br/habitacao/biblioteca-snh/61-snh-secretaria-nacional/biblioteca/164-banco-referencial-de-plhis (consulta em: 20/08/2019)

https://www.mdr.gov.br/habitacao/biblioteca-snh/61-snh-secretaria-nacional/biblioteca/164-banco-referencial-de-plhis (consulta em: 20/08/2019)

SÃO PAULO, SÃO PAULO. PROJETO DE LEI № 619/16. Plano Municipal de Habitação de São Paulo. 2016. Disponível em: <https://gestaourbana.prefeitura.sp.gov.br/wp-content/uploads/2014/08/20161221_PMH_PL_bxa.pdf> Acesso em: 30/08/2019.

SÃO VICENTE. PLHIS - Plano Local de Habitação de Interesse Social, 2010. Disponível em:<https://docplayer.com.br/7548028-Plhis-plano-local-de-habitacao-de-interesse-social.html>.Acesso em: 10/09/2019.

https://www.mdr.gov.br/habitacao/biblioteca-snh/61-snh-secretaria-nacional/biblioteca/164-banco-referencial-de-plhis (consulta em: 10/09/2019)

https://www.mdr.gov.br/habitacao/biblioteca-snh/61-snh-secretaria-nacional/biblioteca/164-banco-referencial-de-plhis (consulta em: 20/09/2019) 